\title{
Effect of Quenching Media on Laser butt Welded Joint on Transformed -Induced Plasticity (TRIP) Steel
}

\author{
Khot Rahul $\mathbf{S}^{1,2}$, Venkateswara Rao $T^{3}$ \\ ${ }^{1}$ Mechanical Department, K L University, Vijayawada, Andra Pradesh, India \\ ${ }^{2}$ Marathwada Mitra Mandal's College of Engineering, Karvenagar Pune, India 411052 \\ ${ }^{3}$ Mechanical Department, DBS Institute of Technology, Kavali, SPSR Nellore, Nellore, Andra Pradesh, India \\ Email Id.: rahul.khot18@gmail.com
}

\begin{abstract}
The characteristics of laser welding joint were investigated by bearing in mind the effect of normal materials, Post-heated materials and cooled with different media i.e. water and air on microstructure, microhardness distribution and tensile strength on Transformation-Induced Plasticity (TRIP) Steel. In our, experiments The Normal - Air (N- A) specimen gives ultimate tensile strength is very improved as $575.05 \mathrm{MPa}$ with the elongation as $14.8 \%$ as compare to $524.37 \mathrm{MPa}$ ultimate tensile strength and $22.8 \%$ elongation in case of N-N specimen which gives $9.66 \%$ change in ultimate tensile strength. As its ultimate tensile strength and percentage elongations decrease, the outcome of N-W Prepared samples also follows the inverse pattern. The tensile strength affects reversal with respect to lower cooling rate of the welded specimen during air quenching and the faster cooling rate leads to more distortion in water quenching. Finally, microstructure, microhardness behavior of Base Metal (BM), Heat Affected Zone (HAZ) and Fusion Zone (FZ) was investigated and discussed.
\end{abstract}

Key words : Butt weld joints, Heat Treatment, Laser beam welding, Transformed Induced Plasticity (TRIP) Steel

\section{INTRODUCTION}

The automobile manufacturing sector is changing significantly as they are interested in improving the performance of vehicles. One of the ways to achieve this is by reducing the weight of the vehicle so the fuel consumption is improved. In order to do this large amount of research is going on in the field of materials [1-3].Compared to arc welding, gas welding or any other modern welding methods, the energy required to create welded joints with Laser welding is comparatively low. In addition, the cooling of the as-Post pared welded joint was reasonably quick and thus affects the characteristics of the joint while it is still in operating condition. In the recent decades the use of Advance High Strength Steel (AHSS) plays a vital role in body manufacturing of Automotive. One of the excellent materials falls under this head is Transformed Induced Plasticity (TRIP) Steel is high strength and low alloy steel having multiphase structure containing Retained Austenite (RA) and Bainite in association withwithimproved elongation properties and ultimate strength just because of ferrite which satisfying intensified automobile industry requirement for good formable high strength steel [4]. The Retained Austenite is going to convert into martensite with ample amount of activation energy is induced during transformation which improves work hardening property of materials significantly [5]. TRIP effect was first investigated by Wassermann [6].

The most common techniques used to join the metals are Arc welding, TIG, MIG, etc which is renowned from other forms of mechanical connections, such as riveting or bolting. Laser welding is prominent process used for cutting, joining and contact less method for achieving good result. Because of extensive characteristics of process widely applied in diversified sectors like medical industries probably in instrument joining, dental application, space work, energy sector, automotive and many more [7]. science 25 Years ago Laser is used for different Industrial applications for material cutting, joining, Sintering with different types of laser like $\mathrm{CO} 2$ followed by the Nd: YAG-laser. [8-9].The laser welding technology has distinct advantage which provides high scanning velocity, due to quick heat removal and instant process narrow heat affected zone created and distortion in relative region. As the process is quite simple and controlling is excellent with power, velocity, incident angle, diameter of laser beam, types of laser, focal length, high intensity source which will reflect into output of the joint in the form of mechanical properties like strength, ductility, hardness, metallurgical properties, thermal distortion, good penetration depth etc.[10]. One of the major advantages of Laser welding is that, without use of filler materials, can produce a joint.The responsiveness of different materials is also affecte $\mathrm{d}$ by broad variations in thermal properties and low metal co mpatibility[11-15]. Laser welding has a distinct advantage like

Capability to regulate welding, repeatability and quick autom atic profiling which will control the weld profile with an extremely narrow heat affected area [16-18]. Very few researchers has done a work in the field of Heat treatment and 
its characterization [19-20] on laser welding joint in low carbon high strength steel like TRIP steel.

The present work deals with Joint manufactured by Nd:YAG laser welding on Transformed Induced Plasticity (TRIP) Steel sheet with $2 \mathrm{~mm}$ with different cooling media and investigating its effect on the Ultimate strength, elongation, microstructure and microhardness of joint. A more concentration is done on the Heat Affected zone (HAZ) and Fusion Zone (FZ).

\section{METHODOLOGY}

For this study the $2 \mathrm{~mm}$ sheet thickness without coating in the form of a large cold drawn is used which is supplied for Nextgen. The materials are heated to revitalization temperature and cooled in different media like water and air to room temperature. The chemical compositions are as indicated in Table No.1

Table No. 1 Chemical compositions of as received TRIP

\begin{tabular}{|l|l|l|l|l|l|l|l|l|}
\hline $\begin{array}{l}\text { Elem } \\
\text { ent }\end{array}$ & $\mathrm{C}$ & $\mathrm{Mg}$ & $\mathrm{Si}$ & $\mathrm{Ni}$ & $\mathrm{Cr}$ & $\mathrm{Mb}$ & $\mathrm{P}$ & $\mathrm{Al}$ \\
\hline$\%$ & $\begin{array}{l}0.03 \\
4\end{array}$ & 0.2 & $\begin{array}{l}0.02 \\
2\end{array}$ & $\begin{array}{l}0.03 \\
3\end{array}$ & $\begin{array}{l}0.01 \\
9\end{array}$ & $\begin{array}{l}0.00 \\
7\end{array}$ & 0.02 & 0.04 \\
\hline
\end{tabular}

The joint was prepared with a weld line perpendicular to the sheet orientation for the identical sheets in butt weld joint form by using Nd:YAG laser. The cross section of the plate is in the dimensions of 200X20X2 mm according to the ASME E8 standards. As shown in Fig. No. 1 the plates were cut into two halves identical with each other and then joined by using Nd: YAG laser welding.. The Fig. No. 2 shows the samples are prepared in different quenching media. The parameters which were fixed with the systems were tabulated in Table No. 2. Used with a 3-phase, $50-60 \mathrm{~Hz}$ frequency with a maximum power of $13.5 \mathrm{~kW}$ and a power source of 400-480V \pm 10 , the GmbH 56218 series laser system (Karlich Germany) The butt welding was carried out using six axis $\mathrm{ABB}$ robot arms that contain good welding process efficiency with a minimum capacity of $6 \mathrm{Kg}$ of payload. The characterization of the micro structure was conducted with optical microscopy (Reichert, Austria) and field emission scanning electron microscopy (FESEM, ZEISS Gemini SEM 450, Germany) on as-welded TRIP steel plates. The tensile test has been carried out with Model No using SAR Testing Systems. STS 248 with a working speed of $5 \mathrm{~mm} / \mathrm{min}$ and machine accuracy of $\pm 1 \%$.

Table No. 2 Laser welding Parameters set for the experimentation

\begin{tabular}{|l|l|l|l|l|l|}
\hline $\begin{array}{l}\text { Laser } \\
\text { welding } \\
\begin{array}{l}\text { Gun } \\
\text { angle }\end{array}\end{array}$ & $\begin{array}{l}\text { Power } \\
\text { of } \\
\text { Laser }\end{array}$ & $\begin{array}{l}\text { Focus } \\
\text { Distanc } \\
\text { e }\end{array}$ & $\begin{array}{l}\text { Beam } \\
\text { Identifica } \\
\text { tion }\end{array}$ & $\begin{array}{l}\text { Speed } \\
\text { of } \\
\text { Gun }\end{array}$ & $\begin{array}{l}\text { Gap } \\
\text { betwee } \\
\text { n plates }\end{array}$ \\
\hline $90^{\circ}$ & $\begin{array}{l}2000 \\
\text { W }\end{array}$ & $\begin{array}{l}113 \\
\mathrm{~mm}\end{array}$ & $60 \mathrm{~W} 113$ & $25 \mathrm{~m} / \mathrm{s}$ & 0 \\
\hline
\end{tabular}

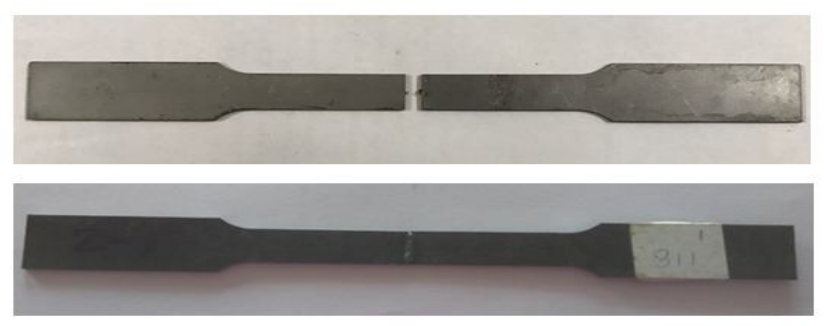

Figure No.1 Sample prepared for experimentation a) Cut piece b) Specimen after Joint
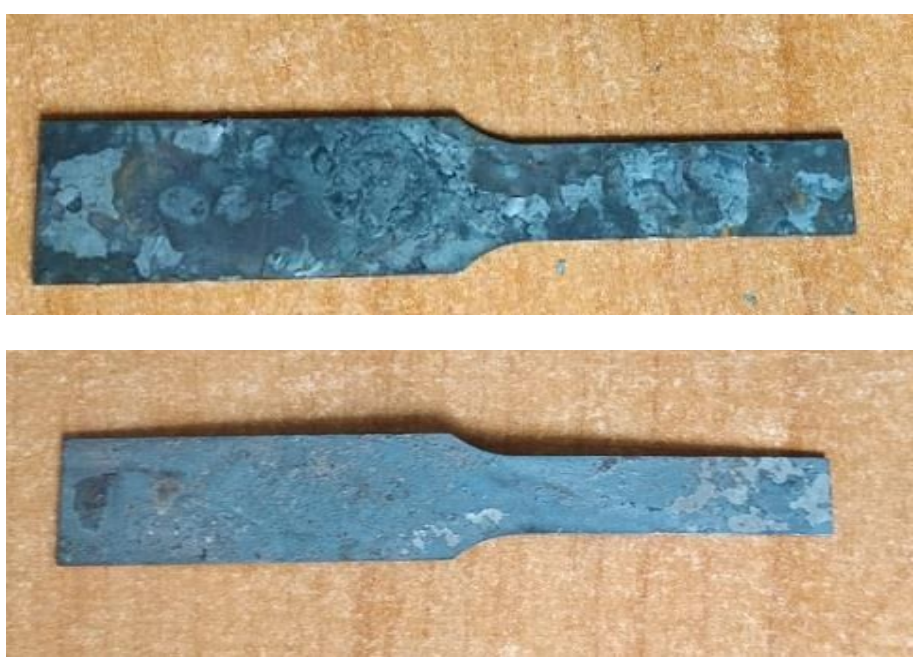

Fig. No.2 Water Quenched Sample and Air Cooled Sample

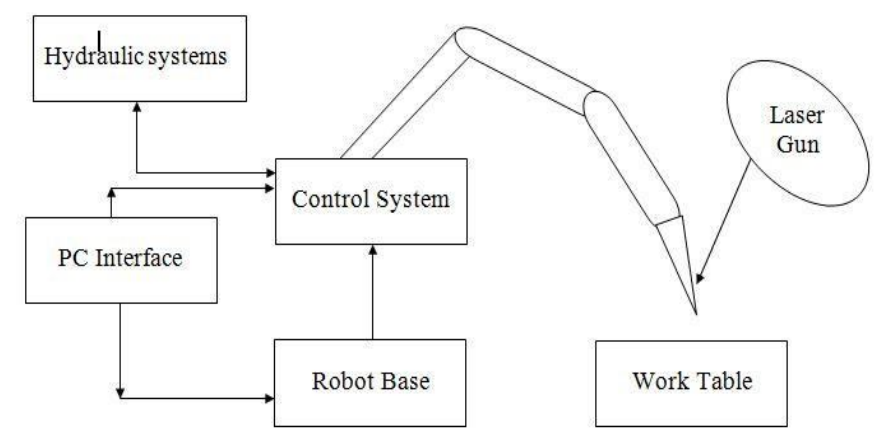

Figure No.3 General Layout of machine setup

The different quenching mediums were incorporated as shown in Table No. 3 and effects were analyzed. Firstly the samples were heated to re crystallization temperature and then cooled in different mediums like Air and distilled water at room temperature. Afterwards the Laser welding process was done with different combinations, like joining without heat treatment samples $(\mathrm{N}-\mathrm{N})$, normal samples with water quenched (N-W) and Normal samples with Air cooled Samples (N-A). The effects of this were analyzed and discussed. 
Table no. 3 Heat treatment Parameters

\begin{tabular}{|r|c|c|c|c|}
\hline $\begin{array}{c}\text { Sr. } \\
\text { No. }\end{array}$ & Type of quench & $\begin{array}{c}\text { Soaking } \\
\text { Temp. }\left({ }^{\circ} \mathrm{C}\right)\end{array}$ & $\begin{array}{c}\text { Soaking } \\
\text { time (Hrs. })\end{array}$ & $\begin{array}{c}\text { Quench Temp. } \\
\left({ }^{\circ} \mathrm{C}\right)\end{array}$ \\
\hline 1 & Air & 950 & 02 & Room temp. \\
\hline 2 & Water & 850 & 02 & 30 \\
\hline
\end{tabular}
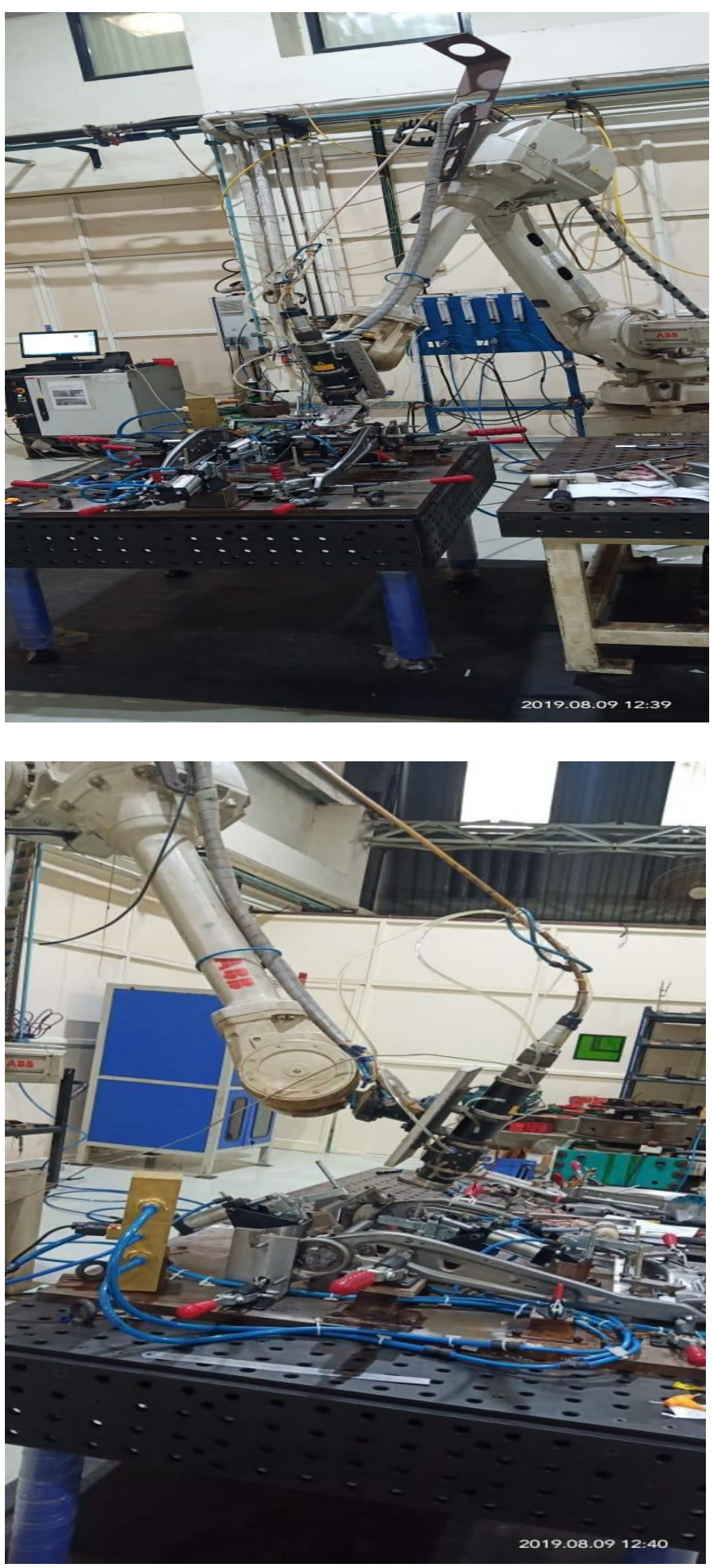

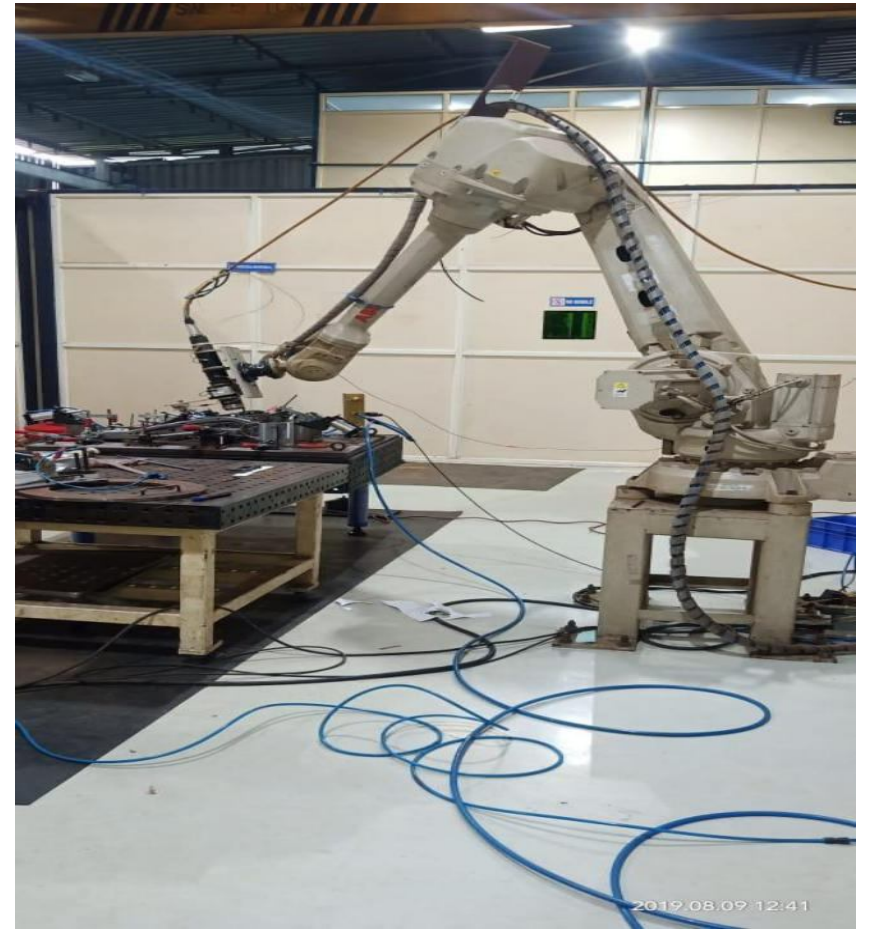

Figure No.4 ABB six axis robot arms

\section{RESULT AND DISCUSSION}

\subsection{Mechanical Properties}

As the testing was done on the samples the details are tabulated in the Fig. No.5. It was clearly indicated that Ultimate Tensile strength in case of sample prepared with condition Normal with Air quenched (N-A) having maximum ultimate strength as $575.05 \mathrm{MPa}$, while with joint prepared using condition Normal sample with Water quenched $(\mathrm{N}-\mathrm{W})$ sample was having strength $512.65 \mathrm{MPa}$. It has seen improved joint strength as compared to the base material. Similarly, the joint manufactured with condition N-A's load carrying capacity was much greater $(12.62 \mathrm{KN})$ compared to $\mathrm{N}-\mathrm{N}$ and $\mathrm{N}-\mathrm{W}$ as $12.38 \mathrm{KN}$ and $12.16 \mathrm{KN}$, respectively. It was because the time it took for the material to cool was significant, which improved the material strength. Because of the rapid quenching it prevents the formation of equilibrium goods. The FCC keeps more carbon in solution, and after rapid cooling, wants the crystal structure to return to its BCC form. This cannot be attributable to trapped carbon atoms. The net result is a twisted crystal structure labeled tetragonal based onthe body. Fig. No. 6 shows the variation of ultimate load required to fail the component along with Ultimate strength and percentage deformation. This plot was developed considering the values of different sample conditions in accordance with $\mathrm{N}-\mathrm{W}, \mathrm{N}-\mathrm{N}$ and $\mathrm{N}-\mathrm{A}$. The sequence was maintained in way that variation of the parameter were in upward directions. So the maximum value were related to the condition of NormalAir condition (N-A). So the load withstanding capacity of the $\mathrm{N}-\mathrm{A}$ joint was high as compare to remaining two conditions viz. N-N and $\mathrm{N}-\mathrm{W}$. 


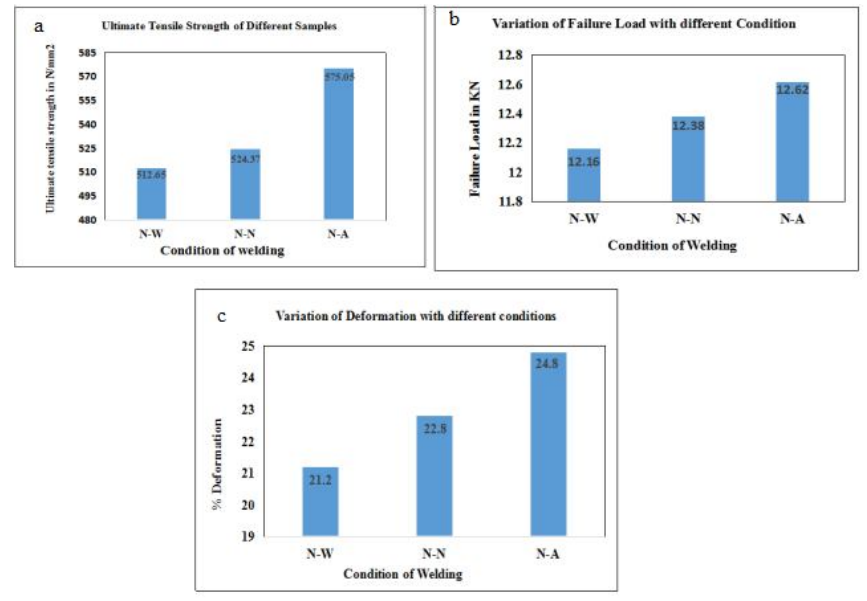

Fig. No. 5 Variation of a) Ultimate tensile strength b) Total deformation c) Failure load applied on various samples and

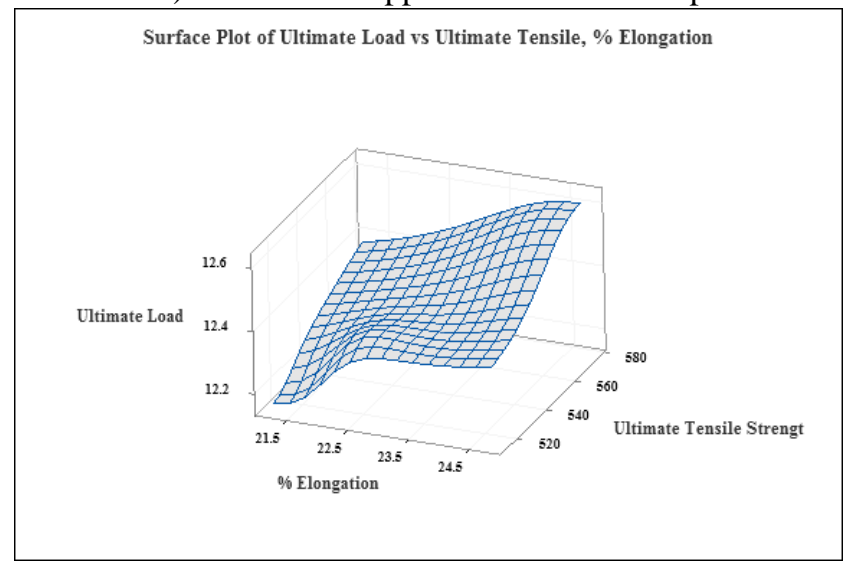

Fig. No. 6 shows the contour plot of the Ultimate load, Tensile Strength and \% elongation of the sample

\subsection{Metallurgical Properties}

The steel structure and grain size varied as the velocity increased, and the fractured surface showed a form of ductile fracture. It can be concluded from above result that he existence of voids may have been created during the welding process due to the oxides and nitrites phases being formed [15]. Based on Fig. No. 7, it has be seen that the fraction of Martensite is found mainly in the HAZ adjacent to the FZ in instigated forms as the quenching temperature and time was less the structure deviated as per the N-W Sample in Fig. No 7. Nevertheless, bainite and ferrite gradually replaced the martensite fraction in the HAZ, as it approached the base steel. The Microstructure shown in Fig No. 7 were shows $\mathrm{HAZ}$ region of $\mathrm{N}-\mathrm{N}$ and $\mathrm{N}-\mathrm{W}$ conditions were due to rate of cooling. All the regions from Normal- Normal (N-N) sample was shown in Fig. No 8 which was clearly shown different boundaries of the regions as Heat energy Affected Zone (HAZ), Base Material (BM) and Fused Zone (FZ).

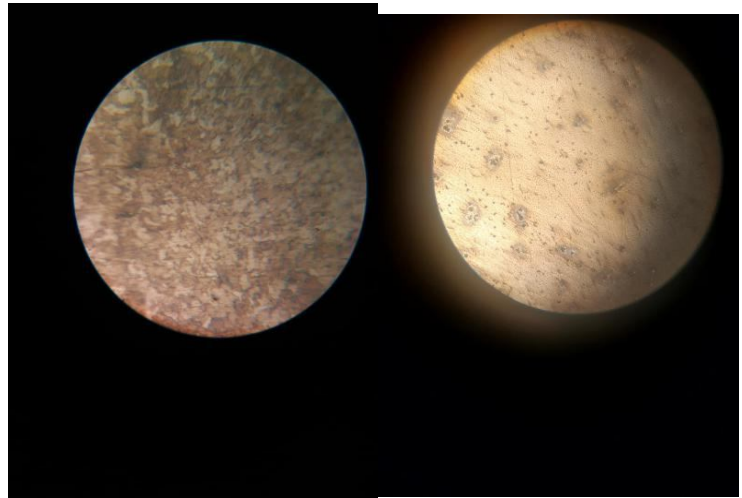

Fig. No. 7 Microstructure of Welded sample with condition $\mathrm{N}-\mathrm{N}$ and $\mathrm{N}-\mathrm{W}$ samples

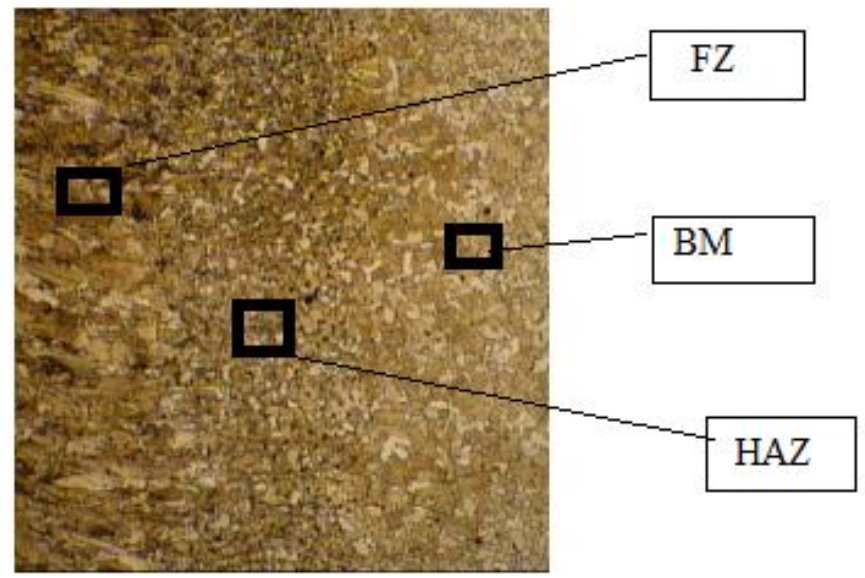

Fig. No. 8 Microstructure of Welded sample with condition N-N Heat energy Affected Zone (HAZ), Base Material (BM) and Fused Zone (FZ) mainly consist of Martensite

. In addition,the scale of the ferrite grain occurred in heat energy affected region was affected as it is smaller than that of the base metal steel equivalent. Although the Fused Zone shows martensite with columnar grain structure in its entirety, the boundary between the three zones is widely demarcated, demonstrating a multiphase microstructure consisting of ferrite, bainite, and a small amount of austenite retained. The FESEM Images are shown in the Fig. No.9 shown the structure of material after water quenched and Air cooled.

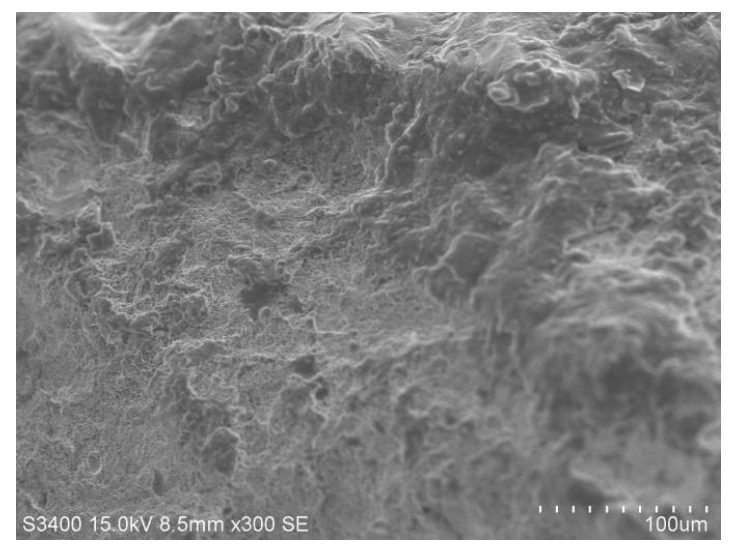




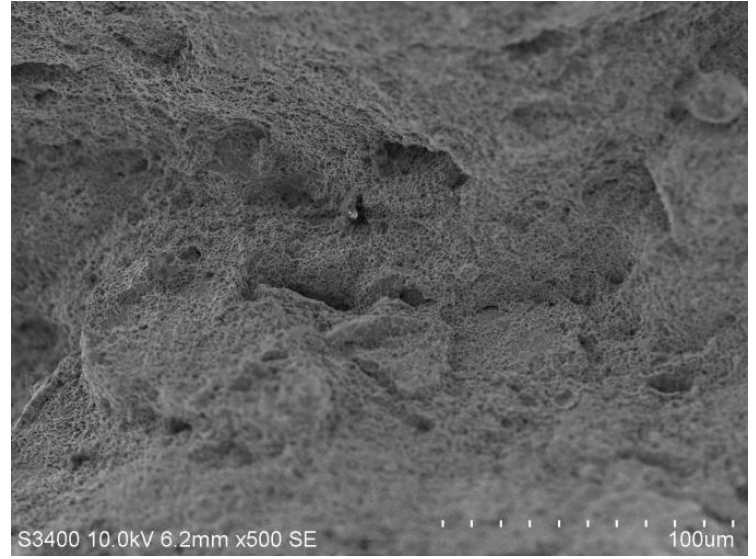

Fig. No. 9 FESEM Images of Water quenched and Air cooled samples

\subsection{Hardness}

The Heat affected zone carries maximum value of hardness relatively than that of the Fusion zone and the base metal. The hardness of weld metal, due to formation of martensite structure, is higher than that of the base metal. The hardness value in water quenched sample was higher that of the Air cooled and normal sample. Due to the stress relief process the lowest hardness value was $(232 \mathrm{Hv})$ and this process allows dislocation motion in the structural system. The least hardness value after quenching the specimen in $850^{\circ} \mathrm{C}$ water was $(252.3$ $\mathrm{Hv})$

\section{CONCLUSION}

The investigation of different iterations performed and results are as follows

1. The mechanical tensile strength is improved in the case of joint prepared by the condition of Normal to Air Cooled sample (N-A) by $9.66 \%$ with respect to the joint manufactured by Normal - Normal (N-N) condition and that of with Normal- Water Quenched sample $(\mathrm{N}-\mathrm{A})$ by $12.17 \%$. So the heat treatment process followed by air cooling is admirisible.

2. The total deformation is also improved by $8.77 \%$ and $14.5 \%$ in above respective conditions

3. The load carrying capacity of the joint is predominantly increased from $12.38 \mathrm{KN}$ to $12.68 \mathrm{KN}$ i.e. $2 \%$ from $\mathrm{N}-\mathrm{N}$ joint and $3.97 \%$ (12.16 to $12.62 \mathrm{KN}$ ) from $\mathrm{N}-\mathrm{W}$ joint.

4. Also microstructure and hardness are improved to certain extend, that improve above parameters

\section{ACKNOWLEDGEMENT}

The authors would like to thanks Mr. Hashad Natu Managing Director Magod Fusion Technologies Pvt. Ltd. (MFTPL) Pune for their valuable help for LaserWelding experimental setup.

\section{REFERENCES}

1. Aslanlar S. The effect of nucleus size on mechanical properties in electrical resistance spot welding of sheets used in the automotive industry. Materials \& Design Volume 27, Issue 2, 2006, Pages 125-131

2. Zhang XQ, Chen GL, Zhang YL. Characteristics of electrode wear in resistance spot welding dual-phase steels.Materials and Design 29 Issue 1, 2008 Page no.279-283 DOI: 10.1016/j.matdes.2006.10.025

3. Sun YF, Fujii H, Takaki N, Okitsu Y. Microstructure and mechanical properties of dissimilar Al alloy/steel joints prepared by a flat spot friction stir welding technique.Materials \& DesignVolume 47, May 2013, Pages 350-357

4. Faruk Varol, Erman Ferik, Ugur Ozsarac, Salim Aslanlar Influence of current intensity and heat input in Metal Inert Gas-brazed joints of TRIP 800 thin zinc coated steel plates Materials and Design 52 December 2013 Page no. 1099-1105

5. Choi ID. Deformation behavior of low carbon TRIP sheet steels at high strain rates. ISIJ International, Vol. 42 Sept. 2002, No. 12, page no. 1483-1489

6. Wassermann G. Untersuchungen an einer Eisen-Nickel Legierung ber die Verformbarkeit Whrend der a-c Umwandlung. Archiv Eisenhttenwesen 1939; 10(7) Page no.321-25.

7. M.R. Nekouie Esfahani, J. Coupland, S. Marimuthu, Numerical simulation of alloy composition in dissimilar laser welding, Journal of Materials Processing Technology 224 (2015) 135-142.

8. Dr.-lng. P. Hoffmann, Prof. Geiger, Prof. Dr.-lng. Dr. h. c. M. Geiger, Recent Developments in Laser System Technology for Welding Applications, Annals of the ClRP Vol. 44/1/1995

9. A. Gursel, Crack risk in Nd: YAG laser welding of Ti-6Al-4V alloy, Materials Letters (2016), doi: http://dx.doi.org/10.1016/j.matlet.2016.12.112

10. Casalino, G., Guglielmi, P., Lorusso, V.D., Mortello, M. Peyre, P., Sorgente, D., Laser offset welding of AZ31B Magnesium Alloy to 316 Stainless Steel. Journal of Materials Processing Technology http://dx.doi.org/10.1016/j.jmatprotec.2016.11.020

11. Khot Rahul S., T. Venkateswara Rao, Abhishek Keskar, H. N. Girish, Puttaswamy Madhusudan, Investigation on the effect of power and velocity of laser beam welding on the butt weld joint on TRIP steel, Journal of Laser Applications 32, 012016 (2020); https://doi.org/10.2351/1.5133158

12. Zicheng Zhang, Yanmei Li, Ken-ichi Manabe and Fuxian Zhu, Effect of Heat Treatment on Microstructure and Mechanical Properties of TRIP Seamless Steel Tube, Materials Transactions, Vol. 53, No. 5 (2012) pp. 833 to 837

13. GAO Yi, HE Zhong-ping, HE Yan-lin, LI Lin, FU Ren-yuand, Zhou Lei, Effect of Heat Treatment on Microstructure and Mechanical Properties of TRIP Steel Sheets Containing Aluminium, Advanced Materials Research Vols 391-392 (2012) pp 554-558 
14. H. K. D. H. Bhadeshia, "Problems in the welding of automotive alloys," JournalScience and Technology of Welding and Joining Volume 20, 2015 - Issue 6 Page no.451-453

15. P. Dinesh Babu1, P. Gouthaman and P. MarimuthuEffect of Heat Sink and Cooling Mediums on Ferrite Austenite Ratio and Distortion in Laser Welding of Duplex Stainless Steel 2205Chinese Journal of Mechanical Engineering (2019) Page no. 32 - 50 https://doi.org/10.1186/s10033-019-0363-5

16. ] $\mathrm{K}$ Qi, R Li, G Wang, et al. Microstructure and corrosion properties of laserwelded SAF 2507 super duplex stainless steel joints. Journal of Materials Engineering and Performance, 2019, 28(1) Page no. 287-295.

17. [15] I Calliari, C Gennari, E Hurtado Delgado, et al. Laser welding of plastically deformed lean duplex stainless steel. Metallurgia Italiana, 2018, (1) Page no. $5-10$.

18. S Hu, D Zheng, G Zhao, et al. The efect of welded joint properties on the surface characteristics of laser-welded 2205 duplex stainless steel. Advances in Mechanical Engineering, 2018, 10(9): Page no. 1-11.

19. Bibit Sugito, Agus Dwi Anggono, Aditya Qomarudin. Influence of Annealing and Normalizing Treatment to The Hardness and Microstructure of Friction Stir Welding Al-5052., International Journal of Emerging Trends in Engineering Research, 8(9), September 2020,Page no. 5362-66

20. U.Sudhakar, J.Srinivas, M V A Raju Bahubalendruni. Tensile Behaviour Characterization of AA5251 AA6063 joint Prepared through Friction Stir Welding process, International Journal of Emerging Trends in Engineering Research, 8(9), September 2020,Page no. 5324-29 